\title{
Indicações geográficas (IG) no contexto da modernização da agricultura no vale do São Francisco
}

\author{
Indicaciones geográficas (IG) en el contexto de la modernización \\ de la agricultura en el valle de São Francisco
}

\author{
Protected Geographical Indication (PGI) in the Context of \\ Modernization of the Agriculture Procedures in the Valley of \\ São Francisco
}

\author{
Raimunda Aurea Dias de Sousa \\ aurea.souza@upe.br \\ Universidade de Pernambuco - Câmpus de Petrolina, PE
}

\begin{abstract}
Resumo: O selo IG (Indicações Geográficas) surge quando se percebeu que alguns cultivos oriundos de determinados territórios apresentavam características específicas, atribuíveis à sua origem geográfica, como a uva e a manga do Vale do São Francisco, por isso precisavam ser protegidos de forma legal. Assim, o referido selo tem por finalidade mostrar que o produto apresenta uma origem geográfica específica e que possui qualidades e reputação vinculadas ao local geográfico. Nessa perspectiva, o presente trabalho objetiva analisar as contradições do selo IG no Vale do São Francisco e como o mesmo vem sendo utilizado em seu contrário, ou seja, apenas para negócio, sem levar em conta aquilo que considera importante - as tradições culturais.
\end{abstract}

Palavras Chave: selo IG, tradição, associação, negócio, região.

Resumen: El sello GI (Indicaciones Geográficas) ha surgido cuando se ha percibido que algunos cultivos procedentes de ciertas zonas presentaban características específicas asignadas a su origen geográfico, como uvas y mangos del valle de Sao Francisco, y por tal razón debían ser legalmente protegidas. Por lo tanto, lo ya mencionado sello tiene el propósito de mostrar que el producto tiene un origen geográfico específico, y además que tiene cualidades y reputación que se vinculan a la localización geográfica. En vista de eso, el presente trabajo pretende analizar las discrepancias de los sellos GI en el valle de Sao Francisco y lo que se está utilizando, es decir, llevar a cabo solamente los aspectos de negociación sin tenerse en cuenta lo más importante - las tradiciones cultuales inherentes.

Palabras clave: sello IG, tradición, asociación, negocios, territorio.

Abstract: The seal of Protected Geographical Indication (PGI) comes out when it has been realized that some cultivars coming from a demarcated territory would present specific characteristics inherent to their geographical origin, as it happens to the grape and the mango of the Valley of Sao Francisco; and for that reason, they ought to be protected in a legal manner. This way, aforesaid seal aims to show that the products present a specific geographical origin and owns the quality and reputation bound to that geographical location. Accordingly, this paper intends to analyze some contradictions involving the PGI seal in the Valley of Sao Francisco, and how it is 
being used on a contrary sense, i.e. for business purpose only without even taking into consideration what is much more important: the cultural traditions.

Keywords: PGI Seal, tradition, association, business, territory.

\section{INTRODUÇÃO}

De acordo com o SEBRAE em parceria com o INPI ${ }^{1}$ (Instituto Nacional de Propriedade Industrial), as Indicações Geográficas são divididas em duas espécies: a) Indicações de Procedências (IP) - esta espécie valoriza a tradição produtiva e o reconhecimento público de que o produto de uma determinada região possui uma qualidade diferenciada; $b$ ) Denominação da Origem (DO) - espécie em que as características do território agregam um diferencial ao produto.

No Vale do São Francisco, o pedido de Indicação de Procedência (IP) foi aprovado em 2009, somente para empresas e agricultores filiados à União das Associações e Cooperativas dos Produtores de Uvas Finas de Mesa e Mangas, especialmente, as do Polo Juazeiro/Petrolina.

A Indicação de Procedência para manga e uvas finas de mesa concedida não significa que, historicamente, esses cultivos eram desenvolvidos por pequenos produtores familiares e camponeses. Essa realidade é recente e se dá por uma necessidade de grandes produtores capitalizados e não por um costume local. Portanto, é um modelo criado, em geral, para empresários que trazem em seu bojo o lema "os melhores vencerão", uma vez que é preciso dispor de capital para seguir as normas do selo e da própria união dos associados e cooperados.

Desse modo, as regras criadas a partir do mercado destroem a tradição e a cultura, contrariando o que está explícito no selo: "Os produtos com Indicação Geográfica englobam atributos que incluem a satisfação do consumidor em adquirir algo que contribui para a preservação de uma tradição e de identidade cultural" ${ }^{2}$.

É importante frisar que o termo identidade utilizado nas Indicações Geográficas é tão somente um paradigma da pós-modernidade. Busca-se o indivíduo como leitura social e não classe social, pois o homem enquanto ser social é um ser individual. O tempo histórico não tem significado, é negado, o que importa é a representação de uma história criada pela imposição e vendida como tradição cultural ${ }^{3}$.

A metodologia da pesquisa tem como princípio a dimens ão histórica dialética como garantia da leitura processual da dinâmica dos movimentos internos inscritos na totalidade

1 Autarquia Federal vinculada ao Ministério do Desenvolvimento, Indústria e Comércio Exterior. Tem por finalidade principal - executar, no âmbito nacional, as normas que regulam a propriedade industrial, segundo a Lei 9.279/96 (Lei da Propriedade Industrial - LPI/96), com as seguintes atribuições: concessão de patentes, registro de marcas, averbação de contratos de transferência de tecnologia, além de conceder outros registros. Definição disponível em: www.tecpar.br/appi/ Basico_NITs/Basico.../IndicacoesGeograficas.pdf. Acesso em: 02 nov. 2017.

2 Entrevista concedida pela coordenadora de Incentivo à IG, Patrícia Saraiva, esclarecendo dúvidas sobre o registro. Disponível em: https://www.fao.org.br/igvpa.asp. Acesso em: 02 nov. 2017.

3 Análise do termo identidade na sociedade capitalista baseado em informações de notas de aula da disciplina Teoria Agrária proferida por Alexandrina Luz CONCEIÇÃO, na Universidade Federal de Sergipe, em 19 jan.2009. 
das relações sociais mundiais, sendo estruturada em torno da organização de uma pesquisa bibliográfica e de práticas de campo que se definiram em análise qualitativa/quantitativa para o resgate de experiências de vida e de trabalho a partir de instrumentos qualitativos como depoimentos e consultas de documentos para obtenção dos dados.

\section{O SELO IG E O MERCADO}

A posse de IP aprovada em 2009 para empresas e agricultores filiados à União das Associações e Cooperativas dos Produtores de Uvas Finas de Mesa e Mangas, especialmente, as do Polo Juazeiro/Petrolina, garante aos produtores um instrumento comercial importante para competir nos mercados do Brasil e do exterior (Fig. 1). Conforme Lima (2009), técnica da Embrapa, as regras do selo vão de cuidados com a produção às características finais da fruta, como coloração, tamanho e teor de açúcar. Para ela, "a ideia é que só os melhores (produtores) ganhem o direito de usar o selo".

Atualmente, há no país 14 Indicações Geográficas registradas: 12 Indicações de Procedência - vinho do Vale dos Vinhedos, café do Cerrado Mineiro, carne do Pampa Gaúcho da Campanha Meridional, couro acabado do Vale do Rio dos Sinos, cachaça de Paraty, manga e uva do vale do Submédio São Francisco, vinho e espumantes de Pinto Bandeira, capim dourado do Jalapão, panelas de barro de Goiabeiras, café da Serra da Mantiqueira de Minas Gerais, doces de Pelotas e queijo do Serro - e duas Denominações de Origem: arroz do Litoral Norte Gaúcho e camarão da Costa ${ }^{4}$.

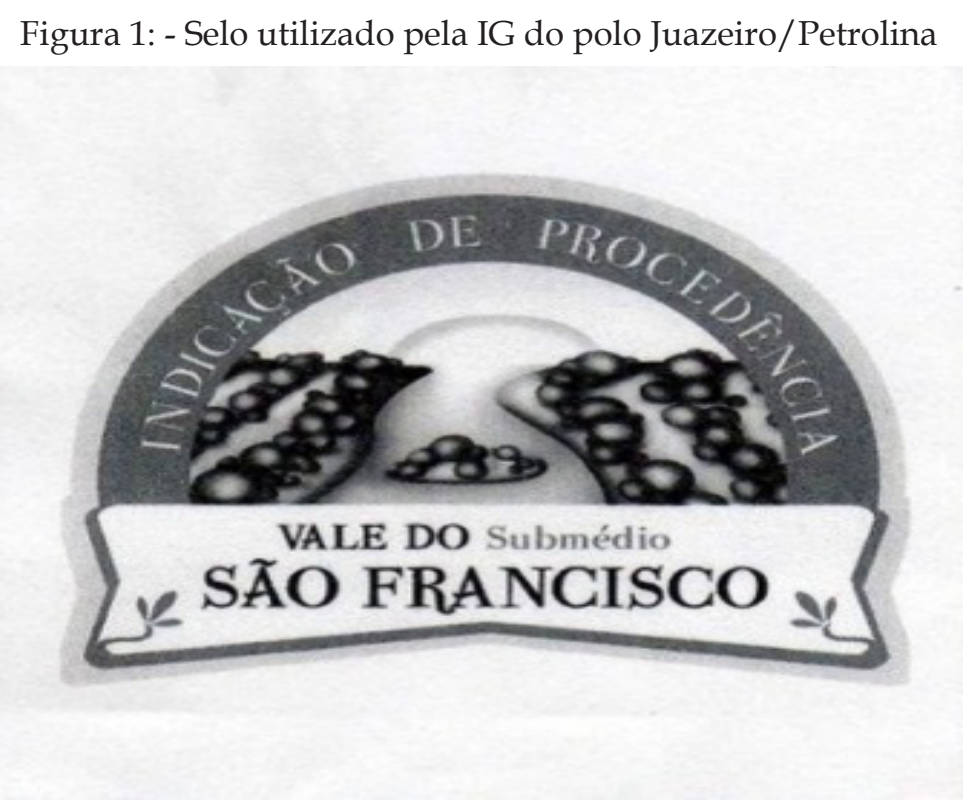

Fonte: INPI/20115.

4 Informações disponíveis em: http://www.sebrae.com.br/customizado/inovacao/acoes-sebrae/consultoria/indicacao-geografica/. Acesso em: 02 nov. 2017.

5 Disponível em: http://www.tecpar.br/appi/Basico_NITs/Basico_2011/IndicacoesGeograficas.pdf. Acesso em: 02 nov. 2017. 
Os argumentos utilizados para conseguir a IP no Vale do São Francisco estão ligados aos atributos de temperatura e luminosidade que induzem também características originais nessas frutas como o aumento da atividade fisiológica das plantas, que podem ser manejadas para produzirem em qualquer período do ano e, no caso das videiras, colher duas safras anuais. Para isso, o uso da ciência tornou-se indispensável, assim como o capital empregado. É nesse sentido que o INPI/SEBRAE (Serviço Brasileiro de Apoio às Micro e Pequenas Empresas) aponta as Indicações Geográficas como ferramentas coletivas de valorização de produtos tradicionais vinculados a determinados territórios. Elas possuem duas funções em principal: agregar valor ao produto e proteger a região produtora.

$\mathrm{O}$ aspecto fundamental a considerar é aquilo que o selo IG compreende como valorização dos produtos tradicionais a determinados territórios. Produtos tradicionais historicamente são ligados a povos tradicionais e seu modo de vida. Este por sua vez, segundo Marques (2004, p.153) se concretiza mediante a "transmissão e reprodução entre gerações de práticas e valores, apresentando mudanças num ritmo mais lento que a modernidade. A tradição é uma forma social típica entre os camponeses, que, diante da sociedade moderna, se afirma em oposição à sua lógica dominante".

A análise de Marques sinaliza para o entendimento que a valorização dos produtos tradicionais vai além da criação de um selo enquanto modelo para garantir ao consumidor a qualidade do produto, assim como a melhor renda aos produtores. Para a autora, proteger a história, tradição e biodiversidade, como recomenda as Indicações Geográficas, tem um sentido contrário ao modo de vida camponês, na medida em que o interesse das IGs é de assegurar aos produtores competividade, melhor remuneração dos produtos pela diferenciação proporcionada pelo reconhecimento no mercado, consequentemente, melhor renda. No universo dos povos tradicionais, a exemplo dos camponeses, as coisas não ocorrem por imposição de um modelo estabelecido como o selo determina, mas por uma necessidade que parte da família e não do mercado. De acordo com Marques (2004, p. 153), o modo de vida camponês é a "forma como um determinado grupo social ou comunidade manifesta a sua cultura", conceituado pela mesma, "como um conjunto de práticas, valores e significado definidos em movimento de reprodução, o qual enfrenta oposição de outros grupos ou classes sociais". (MARQUES, p.153).

A UNIVALE (União das Associações e Cooperativas dos Produtores de Uvas de Mesa e Mangas do Vale do Submédio São Francisco) é a detentora do registo IG. São beneficiados com a indicação 342 produtores distribuídos em 12 associações e cooperativas, que integram a UNIVALE, o que corresponde a mais de $90 \%$ dos produtores da região de Petrolina (PE) e Juazeiro (BA). Ressalta-se que nem todos os agricultores e empresas irão se valer da IP conferida pelo INPI. Por se tratar de uma marca, apenas os filiados à União das Associações e Cooperativas dos Produtores terão esse direito. Tampouco o selo será aferido para todo o volume de produção dos associados. O uso requer o atendimento a padrões de qualidade e técnicas de produção das frutas, instituídos em regulamento aprovado pela própria associação ${ }^{6}$.

6 Baseadas em informações disponíveis em:http://www.cpatsa.embrapa.br/imprensa/noticias/uvas-finas-de-mesa-e-mangas-cultivadas-no-vale-do-submedio-sao-francisco-ganham-selo-de-indicacao-de-procedencia/. Acesso: 02 nov. 2017. 
Nesse sentido, as IGs são analisadas pelo SEBRAE como positivas para as economias locais e dinamismo regional porque proporcionam o real significado da criação do valor local. É um antagonismo, quando se depara com a realidade e se percebe que o 'valor local' é criado em benefício da classe que dispõe de condições para controlar a riqueza da produção e cujo valor tem um único significado - troca no mercado, para obtenção do lucro.

Uma vez em que o universo camponês não tem espaço na economia de mercado, como explica Martins (2003, p.81),

O mundo do camponês e a identidade do camponês não são necessária ou fundamentalmente constituídos por antagonismos internos à sua situação social. Eles são destruídos pelos antagonismos sociais. Se eventualmente houver antagonismos entre o camponês e o proprietário da terra, o que é menos comum na situação brasileira, esse é um antagonismo que vem de "fora" da situação camponesa.

Um modelo criado como símbolo de desenvolvimento local, na análise de Shanin (2008), é inútil e perigoso. Segundo esse autor, em se tratando de modelos é importante que isso seja destacado para que se possa notar a diferença existente entre o conceito e a realidade, sob pena de perder-se a capacidade de entende-la. Por essa razão, o modelo de produção da uva e manga imposto pelos diversos selos, especialmente, o IG, apresenta um grande distanciamento da economia familiar e dos valores estabelecidos pelo modo de vida familiar. Para Shanin (2008, p.27)

... a economia familiar tem seus próprios modelos, suas próprias estruturas e seu próprio significados primordial que não desaparece. Por isso, sob certas condições, a economia camponesa é mais eficiente do que economias não camponesa. Os membros da família e o modelo familiar básico de bem-estar econômico estão envolvidos de forma particular num sistema de uso do trabalho que não é trabalho assalariado, mas trabalho familiar. Daí a sua capacidade para resolver problemas que outros tipos de economia não resolveriam de uma maneira tão eficaz e pouco dispendiosa.

Diante do exposto, não é um modelo copiado da Europa e aplicado no Vale do São Francisco ou em outro local do Brasil que garantirá a 'ordem e progresso'7 de determinado território, mas o respeito aos que utilizam a terra como condição de sua existência, enquanto valor de uso.

Nesse entendimento, território difere da forma utilizada pela IG. Para os idealizadores do selo, território é tão somente um recorte geográfico que se diferencia de outro pela qualidade do produto produzido e pela quantidade expressiva para alcançar escalas diferenciadas. Assim, as IGs isolam as áreas pela produção de uma suposta 'cultura ${ }^{8 \prime}$ como

7 No catálogo das Indicações Geográficas, logo na página 12 é estampada a Bandeira do Brasil com a frase "Ordem e Progresso", o que, de forma velada, sinaliza que é selo uma alternativa de sair das crises financeiras e, assim, manter a ordem, o consenso e obter progresso. Em análises aos documentos do selo, fica evidente que o indivíduo é que deve procurar as melhorias ou quando muito associado a outros somente como um requisito do selo, mas na prática todos competem entre si.

8 Nesse caso, cultura está ligada a cultivo, ou seja, tipo de cultivo, aquilo que é produzido na terra. Alexandrina Luz CONCEIÇÃO. Notas de sala de aula, da disciplina História do Pensamento Geográfico, da Universidade Federal de Sergipe, em 27 de maio de 2010. 
se elas não fizessem parte de uma totalidade, justamente porque são tidas como 'melhores'. Por essa razão, a agricultura irrigada do Polo Juazeiro/Petrolina, com as características climáticas associadas ao uso intensivo de tecnologia, é tida como diferencial que a separa de outras partes do Brasil e de todo planeta.

Nesse sentido, é necessário ocultar as contradições advindas da concretude da concepção de território. Este por sua vez, na Geografia Crítica, expressa conflito de classe, relações de poder, apropriação do espaço ${ }^{9}$. Dessa forma, entender as relações, que perpassam a utilização dos selos no Polo, é entender território, segundo Conceição (2005, p.169), como "categoria fundamental, pois permite observar que a espacialização da miséria se territorializa a partir das relações de poder, de domínio dos fluxos de mercado, controlados por quem domina o afluxo de capitais". Seguindo essa análise, ser proprietário do capital é imprescindível à obtenção de qualquer selo, particularmente o IP, o que significa que, nesse universo, os pequenos produtores, camponeses ou não, estão fora.

Contudo, como o lucro não é objetivo dos pequenos produtores, em especial os camponeses, o selo passa a não ter nenhuma importância. Para eles, na interpretação de Marques (2004, p. 155), a terra para o trabalho é o importante. Desse modo, território passa a ser

... o lugar da realização de um presente não ausente, onde a mediação das abstrações concretas é relativizada, dando vez a uma inserção mais imediata das pessoas no munda da vida. É o lugar da apropriação, do uso e da realização do trabalho não alienado.

Dentro dessa interpretação, percebe-se que o discurso de valorização dos produtos tradicionais de que se vale a IG é, na verdade, uma artimanha do sistema do capital para manter o território sobre seu controle, desenvolvendo cultivos como a manga e uva fina de mesa, no Vale do São Francisco, contrários aos que eram feitos pelos pequenos produtores familiares, camponeses e ribeirinhos. A produção desses sujeitos era voltada para agricultura de chuva e agricultura de beira-rio ${ }^{10}$ cujo sistema de irrigação era executado, a princípio, com rodas d'água. Na primeira, destacava-se o cultivo de feijão de corda e macassar, mandioca e milho; já, na segunda, desenvolvia-se cebola, arroz, feijão mulatinho, melancia, melão, tomate e uva. Esta, mesmo plantada de forma tradicional na margem do rio, já nasceu como um negócio empresarial, tendo início em Floresta (PE) e, mais precisamente, em Santa Maria da Boa Vista (PE), com produção de uva in natura atrelada à vinicultura. Somente a partir dos anos de 1985, a fruticultura se firma no Polo Juazeiro/Petrolina. Este cultivo, portanto, nada tem de tradicional.

É relevante frisar que a produção de uva é também um destaque na produção de vinho do Vale e tem servido para expandir o turismo agrícola. "Além de agregar valor, a

9 Alexandrina Luz CONCEIÇÃO. Notas de sala de aula, da disciplina História do Pensamento Geográfico, da Universidade Federal de Sergipe, em 11 de maio de 2010.

10 A divisão em agricultura de chuva e agricultura de beira-rio no Vale do São Francisco é encontrada em: ANDRADE, Manoel Correia. (1983). 
IG proporciona o desenvolvimento socioeconômico da região, a organização dos produtores e da produção, a valorização do patrimônio cultural e o incremento do turismo"11.

Destaca-se que, na medida em que o cultivo da manga e uva torna-se atividade promissora para o sistema do capital, as terras passam a ser apropriadas para este fim, consequentemente, faz desaparecer o feijão e milho da mesa da população que vive no Sertão, mas, nos discursos proferidos pelos idealizadores desse modelo, a seca deixa de ser um problema, porque o Vale torna-se a partir da irrigação um grande pomar.

Nessa concepção, Andrade (1983, p. 89) afirma que "a irrigação não é um maná dos céus que faça crescer a produção, a produtividade, a renda etc., sem uma contrapartida". Para o autor, do ponto de vista social, ela não melhorou de forma sensível a situação do trabalhador, uma vez que o crescimento da produção e o enriquecimento mais rápido da classe dominante ocorreu em detrimento da grande maioria da população - a classe dominada.

Sendo assim, a substituição dos cultivos tradicionais por manga e uva, reconhecidos pelo Estado como tradicionais e merecedores do selo IG pela alta produtividade, teve e tem um alto custo para os pequenos produtores. Conforme Tosta (2007, p.05), agravou a situação dos trabalhadores e

... se configurou num dos maiores exemplos de expropriação dos camponeses de sua terra e numa considerável mobilidade do trabalho, por conta do crescente desemprego no campo (isso sem falar nas condições precárias de trabalho apresentadas aqueles poucos trabalhadores que conseguem manter-se no processo produtivo), além da crescente degradação da natureza, tendo em vista a mudança de um propósito social, para um propósito meramente econômico-competitivo [...].

A efetividade do selo no Polo Juazeiro/Petrolina acentua a diferença entre grandes produtores e pequenos produtores, fazendo com os últimos fiquem mais endividados para poder competir no mercado.

\section{A FUNÇÃO DO SELO IG NO CONTEXTO DO CONCEITO DE REGIÃO}

A função do IG referente à proteção da região produtora elucida a marca da IP como aquela, cuja finalidade está na valorização comercial e na proteção contra fraudes, coibindo o uso indevido do nome Vale do Submédio São Francisco nas frutas produzidas em outras regiões. Por conseguinte, como os produtos dos pequenos produtores não dispõem desse selo, seus produtos poderiam deixar de serem considerados 'tradicionais'.

Destaca-se que as IGs reforçam em sua segunda função, a categoria geográfica região tão utilizada pelo Estado como necessária ao 'desenvolvimento'. Desse modo, a função do selo de 'proteger a região' no sistema do capital significa apenas o controle e domínio da produção da riqueza.

11 Entrevista concedida pela coordenadora de Incentivo à IG, Patrícia Saraiva, esclarecendo dúvidas sobre o registro. Disponível em: https://www.fao.org.br/igvpa.asp. Acesso em: 02 nov. 2017. 
Harvey (2011) considera que as tensões e contradições no padrão geográfico da acumulação do capital podem dar origem a configurações geográficas, que atingem estabilidade, ao menos, por algum tempo. Para o autor, a região é essa configuração relativamente estável, pois são "economias regionais que alcançam certo grau de coerência estruturada em termos de produção, distribuição, troca e consumo, ao menos por algum tempo. Os processos moleculares convergem, por assim dizer, na produção da 'regionalidade' [...]". (HARVEY, 2011, p.88).

A partir dessa análise, as IGs, no Brasil e em outros países, podem ser compreendidas com base em Harvey (2011, p. 89), quando o mesmo escreve que

As fronteiras de regiões desse tipo são sempre difusas e porosas, mas os fluxos inter-vinculados no âmbito do território produzem uma coerência estruturada suficiente para caracterizar a área geográfica como alguma maneira peculiar com relação a todas as outras áreas de uma economia nacional ou supranacional.

A IG, no Polo Juazeiro/Petrolina, consolida, ainda mais,

a formação de infraestruturas físicas e sociais tanto para apoiar a atividade econômica como para garantir e promulgar valores culturais e educacionais, e muitos outros aspectos da vida cívica, reforça tipicamente a coerência daquilo que começa a surgir como entidade regional no âmbito da economia global. Padrões de comércio e competição, bem como a especialização e a concentração em indústrias-chave ou com combinações e tecnologias, ou então em relações e capacidades de trabalho particulares, interligam economias regionais, de maneira frouxa, na forma de algum todo padronizado de desenvolvimento geográfico desigual. (HARVEY, 2008 p.89).

As diversas IGs, no Brasil, cujas funções de agregar valor ao produto e proteger o mercado produtor daqueles que dispõem de produto similar, mas não sob as mesmas condições de produção, ligam-se a uma necessidade do capital, que é a extração da renda da terra, a partir da mobilidade do trabalho dos espaços que não dispõem das IGs. Portanto, o aparente caos da diferenciação geográfica, de acordo com Harvey (2012, p. 132) "é uma condição necessária para a acumulação do capital começar". Sendo assim, Indicações Geográficas corresponde a Indicações de Desenvolvimento/Subdesenvolvimento Geográfico no interior e exterior delas.

Seguindo a análise, para Harvey (2011), o aspecto fundamental a considerar é, contudo, que uma lógica territorial do poder - uma 'regionalidade' informal, porosa, mas mesmo assim identificável - advém necessária e inevitavelmente dos processos moleculares de acumulação do capital no tempo e no espaço, e que a competição e a especialização inter-regionais nessas e entres economias regionais se tornam, por conseguinte, um aspecto fundamental de funcionamento do capitalismo.

Fica evidente que a IG, enquanto criação do sistema do capital, nada tem a ver com seu objeto declarado de proteção quando menciona que "o bem protegido não é o produto em si, mas os fatores ambientais e humanos associados a ele". (INPI, 2011). No Vale, o bem protegido, ao contrário do que está escrito no guia básico para obter o selo IG 
é de fato o produto e não a natureza e o ser humano enquanto parte integrante dela. Esses são destruídos em nome da riqueza produzida para o mercado, pois, segundo Mészáros (2009), o que agora conta como necessidade não é a necessidade humana dos produtores, mas os imperativos estruturais da própria valorização e reprodução do capital. Os valores de uso se legitimam em relação aos valores de troca.

Sendo assim, o trabalhador somente pode obter acesso a uma determinada classe e quantidade de valores de uso - correspondendo ela ou não às suas necessidades reais - enquanto o capital, com base na unidade reconstituída de necessidade (troca) e produção (reprodução), os legitima como viáveis e lucrativos no interior da estrutura da homogeneização corrente. (MÉSZÁROS, 2009 p.628).

A Geografia da acumulação e da destruição criativa da terra, produzidas pelas Indicações Geográficas, cria conceitos novos para as categorias território e região, especialmente no Polo em estudo, a fim de mostrar que tal selo, como tudo no sistema do capital, é tão somente uma estratégia para produção e reprodução ampliada do capital.

\section{ALGUMAS CONSIDERAÇÕES FINAIS}

Mesmo com o selo IG, tem-se comprovado uma ascensão da manga no mercado externo. $\mathrm{O}$ fato explica-se pela crise na exportação da uva e, a certificação é um dos motivos, além da concorrência e do dinamismo do próprio mercado no sistema do capital, que tem tornado a venda desse cultivo incerta; boa parte das vendas passou a ser efetuada em consignação e terceirizada. Esse fato é muito típico na Europa, quando a empresa não consegue colocar representante próprio para ficar atento ao momento em que a janela se abre para determinado cultivo.

Nesse sentido, justifica-se a expansão da produção da manga para resolver o problema da sobreacumulação da uva, já que devido à concorrência do produto não surgem escoadouros lucrativos. Harvey (2011) atribui ao fato de acumulação por espoliação, quando o capital se abre a novos terrenos de acumulação. É esse o contexto do agro-hidronegócio atuar em todos os setores da economia: o primário (agropecuária, extração vegetal e mineral), secundário (indústria) e terciário (distribuição e comercialização). A maior parte da atividade desse modelo se concentra na indústria e distribuição e uma pequena parte está na agropecuária, embora seja esse setor o seu núcleo de ação como definidor para o repasse das commodities.

Toda a criação de um mercado global, propagandeado no Polo como sinônimo de enriquecimento pelas exportações de frutas, conhecido como agro-hidronegócio deve ser estritamente compreendido, como mecanismo complementar e análogo ao da exclusão da esfera de atividade produtiva, que atinge, dentro de cada país, somente uma parte da população, tanto nos países industrializados como nos países em desenvolvimento. A parte excluída pelo modelo tido 'moderno' logo é incluída na sociedade capitalista para produção, pois "é na produção que se cria riqueza, a partir da combinação social de formas 
de trabalho humano, de diferentes qualificações. Mas é a esfera financeira que comanda, cada vez mais, a repartição e a destinação dessa riqueza". (CHESNAIS, 1996. p. 15).

Sendo assim, os preceitos criados pelo agro-hidronegócio fazem concentrar cada vez mais a produção da riqueza e, com ela, a terra e a água, consequentemente, expulsa os camponeses da terra ou retira sua autonomia de proprietários, tornando-os proletários sem-terra ou com terra.

\section{REFERÊNCIAS}

ANDRADE, Manoel Correia de. Tradição e mudança. Rio de Janeiro: Zahar, 1983.

CONCEIÇÃO, Alexandrina Luz. A Geografia Espaço da Miséria. Scientia Plena, v. 1, n. 6, p.166-170, 2005.

CHESNAIS, François. A mundialização do Capital. São Paulo: Xamã, 1996.

HARVEY, David. Condição Pós-Moderna. 17. ed. São Paulo: Edições Loyola, 2008.

O Novo Imperialismo. 5. ed. São Paulo: Edições Loyola, 2011.

O Enigma do Capital e as crises do capitalismo. São Paulo: Boitempo, 2012.

INPI - Instituto Nacional de Propriedade Industrial/SEBRAE. Indicações Geográficas Brasileiras. Disponível em: http://www.inpi.gov.br/sobre/arquivos/igs_miolo_baixa_20120808.pdf. Acesso em: 02 nov. 2017.

LIMA, Maria Auxiliadora. Frutas do Vale terão selo de qualidade. Disponível em: http:/ / agriculturanovale. blogspot.com.br/2009_07_01_archive.html. Acesso em: 02 nov. 2017.

MARQUES, Marta Inez Medeiros. Lugar do modo de vida tradicional na Modernidade. In: OLIVEIRA, Ariovaldo Umbelino de; MARQUES, Marta Inez Medeiros (orgs). O campo no século XXI: território de vida, de luta e de construção da justiça social. São Paulo: Casa Amarela/ Paz e Terra, 2004.

MARTINS, José de Souza. A Sociedade vista do abismo. Petrópolis: Vozes, 2003.

MÉSZÁROS, Istvam. Para além do Capital. São Paulo: Boitempo, 2009.

SHANIN, Teodor. Lições Camponesas. In: TOMIASI, Eliane; PAULINO, Eliane; FRABRINI, João Edimilson (orgs). Campesinato e territórios em disputa. São Paulo: Expressão Popular/ Ed. UNESP, 2008.

TOSTA, Suzane. O Sertão que virou pomar? Do discurso do estado às contradições do processo histórico. Políticas públicas de irrigação e expropriação camponesa pelo capital: luta pela terra, pelo trabalho e pela água. In: ENCONTRO LATINO AMERICANO DE CIÊNCIAS SOCIAIS E REPRESAS/ ENCONTRO BRASILEIRO DE CIÊNCIAS SOCIAIS E BARRAGENS. 1/2, 2007, Salvador. Anais ... p. 1-16. Disponível em: http:/ / www.neperge.ig.ufu.br/anais.html>. Acesso em: 12 nov. 2017.

Data de submissão: 21/09/2016

Data de aceite: 06/11/2017 